\title{
Integrated Reporting: Case of Lebanon
}

\author{
Malak Bou Diab, Wissam El Hajj, Vera Bou Diab
}

\begin{abstract}
Integrated thinking is the dynamic reflection of the relationships between the organization different operating and functional units and the capitals used as defined by the IIRC. The integrated decision making and actions that take short medium and long term value creation can be attained by adopting integrated thinking. Managers and employees must, however, be aware of a matrix of considerations that combines each of the six capitals (i.e. financial, manufactured, intellectual, human, social and natural) with each functional unit in an organization. Integrated reporting applies principles and concepts that emphasizes on having the reporting process more cohesive, efficient and adopting' integrated thinking'. It improves the quality of the information available to financial capital providers so that the allocation of capital is more efficient and productive. Previous researchers studied integrated reporting and its importance on the welfare of the organization; however, none of the studies investigated practically the effect of integrated reporting on business profitability and sustainability. The aim of this paper is to investigate the variable affecting the adoption of integrated reporting in Lebanon. The researcher will conduct a questionnaire in order to support the paper objectives. The sample will consist of banks, audit firms and multinational companies. A Regression analysis was conducted to verify the relation between the dependent variable (Adoption of integrated reporting) and the independent variables (Education, and Occupying a position in the accounting department).Also regression analysis is used in order to study the impact of the expected challenges on the application of integrated reporting. This paper will help in extending the knowledge and the deep understanding of integrated reporting as a crucial basis in organization development and sustainability.
\end{abstract}

Keywords: Integrated reporting, $<I R>$ Framework, International Integrated Reporting Council, Integrated thinking.

\section{INTRODUCTION}

As businesses face universal competition, technological innovation and more regulation in response to financial disaster, the world economy is constantly changing. The accounting profession argues that the traditional model of financial reporting does not sufficiently meet the information needs of stakeholders to evaluate the current and future performance of a company (Flower, 2015). Stakeholders

Revised Manuscript Received on January 29, 2020.

* Correspondence Author

Malak Bou Diab*, Phd Student, Bucharest University of Economic Studies, Romania, Lebanese International University, Beirut. Email: Malakboudiab@Outlook.Com

Wissam El Hajj, Phd Student, Bucharest University of Economic Studies, Romania. Email: Elhajjwissam18@stud.ase.ro

Vera Bou Diab, Finance Lebanese International University, Beirut. Email: Veraboudiab89@gmail.com

(C) The Authors. Published by Blue Eyes Intelligence Engineering and Sciences Publication (BEIESP). This is an open access article under the CC BY-NC-ND license (http://creativecommons.org/licenses/by-nc-nd/4.0/) want to know the environmental effects of the activities of companies and, most significantly, the financial position. Therefore, companies need to meet the stakeholder's needs by disclosing financial and nonfinancial information in order to be viable and attractive in the business world. The company therefore discloses financial and nonfinancial information through various reports. In support of IR, practitioners of integrated reporting claim that IR provides greater simplicity in the companies promise to sustainability by representing the financial and sustainable performance links in a single document (Adams, 2013; Eccles and Krzus, 2010). To meet the demands, organizations must focus on more than just maximizing profit. The company's long-term value is growing in importance. According to the IIRC the needed step in the corporate reporting development should be the communication on value creation which can be achieved through an integrated report (IIRC, 2013:1). The main aim of this paper is therefore to summarize some insights into integrated reporting, which can support the adoption of IR. In addition, it highlights integrated reporting features such as changes in business performance, integrated thoughts and enhanced reputation. These eventually respond why an integrated reporting system should be adopted by the company.is noted that: 1 . Each author profile along with photo (min 100 word) has been included in the final paper. 2 . Final paper is prepared as per journal the template. 3. Contents of the paper are fine and satisfactory. Author (s) can make rectification in the final paper but after the final submission to the journal, rectification is not possible.

\section{LITERATURE REVIEW}

This section starts with an integrated reporting philosophy and the definition of integrated reporting, and then we expand the basic integrated reporting concepts such as capital and value creation. Moreover, we will emphasize on integrated thinking and the principle-based approach.

\subsection{Integrated reporting philosophy}

A number of changes or developments are brought by integrated reporting. It catalyses a strategic rather than an operational centre, a long-term rather than a short-term outlook. Also it induces a prospective rather than a retrospective analysis. Moreover, it delivers both qualitative analysis and quantitative information. A broader business performance metric is reported in the integrated report compared to compliance with the audit (Owen, 2013:340).

The integrated reporting framework specifically seeks to endorse long-term thinking, and to support decision-making, allocation of capital and to discourage short-term behaviour.

A fundamentally different approach is promoted by the framework.

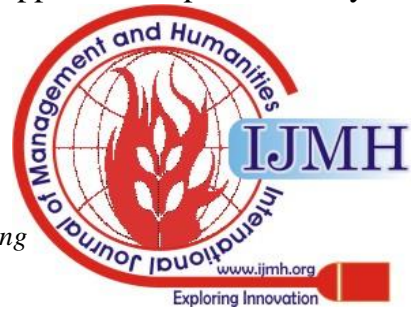


In contrast to the disclosure of current financial and non-financial reports in a snapshot period, integrated reporting is moving towards a more transparent action. It is regularly used in most forms of media and communication (Soyka, 2013).

A more comprehensive, complex and clear representation of the company is provided by integrated reporting. The organization was provided by integrated reporting a richer picture based on a broad dimension of information origin, including subjective and quantifiable data. Integrated reporting matches the need of a user context contrary to the financial supervision which is the shareholder perspective. Accountability is applied when customers, creditors, suppliers, employees, the local community and the general public have all legitimate rights to publish information (Owen, 2013). The priority of the stakeholders depends on the organization social, political and economic perspective. By focusing on conciseness, reliability and materiality, the report details are reduced. Information requirements can be met through a shift to technology-based reporting.

\subsection{Integrated reporting}

Integrated reporting is described as the integrated thinking process that proceeds in a regular integrated report about the creation of value and communication of its aspects. (IR, 2016). It upgrades the organization way of thinking in reporting and planning their business story. The most important point of integrated reporting is creation of value and its effect on the organization. Therefore, integrated reporting is used for the communication of strong, brief integrated story to describe how all assets are involved in the value creation. Integrated reporting is assisting organizations in thinking about their plans, strategies, and managing their risks. Also it helps them to build stakeholders confidence and enhance the organization future performance to drive a universal development in corporate reporting (IR, 2016).

In august 2010, the IIRC was formulated. The accountancy profession, preparers and controllers represent around half of the council participants. The IIRC acknowledged the basic principles of social and ecological accounting, the impact on all resources of the society should be reflected by the company reporting (Flower, 2015). The success of the company is depending on different types of resources and connections. These resources and connections can be comprehended as variety capital forms (IIRC, 2011).

The integrated report should specify the way of value creation through the organizations activity. The measurement of this value is by changing these capitals value (Flower, 2015). Integrated reporting concentrates on the organization's capability of value creation. Integrated reporting stresses on the integrated thinking importance within the company (IIRC, 2013). The mentioned three aspects are integrated reporting fundamental concepts. The three important concepts are the six capitals used and enhanced by the business, the business model of the organization and the value creation (Busco et al., 2013).

\subsection{Capitals}

The capitals discussed in the integrated report are introduced by the IIRC. The capitals are resources and relationships that an organization use or affects. Figure 1 represent the classifications of the capitals and figure 2 elaborate its disregarded (IIRC, 2013).

\subsection{Value creation} creators (IIRC, 2013).

\subsection{Integrated thinking} adopted by organizations but to be presented as a guideline to make sure that there is no capital used or affected is

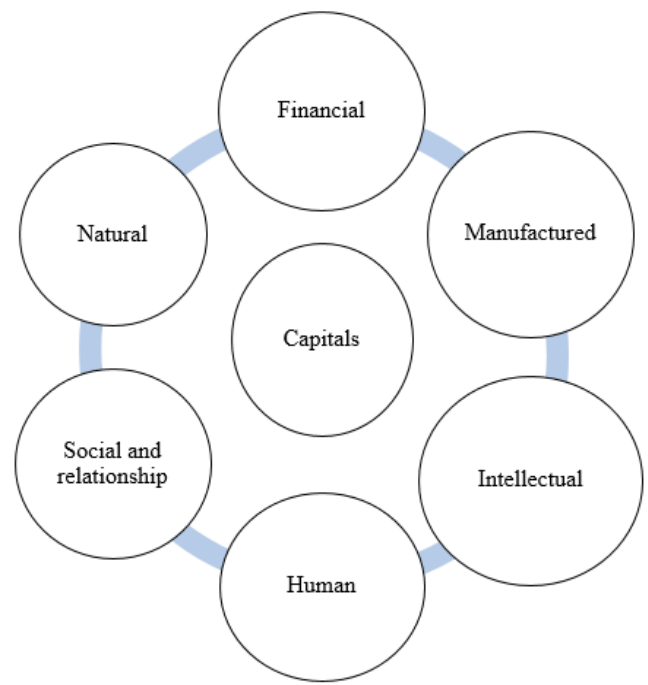

Fig.1. IIRC capitals

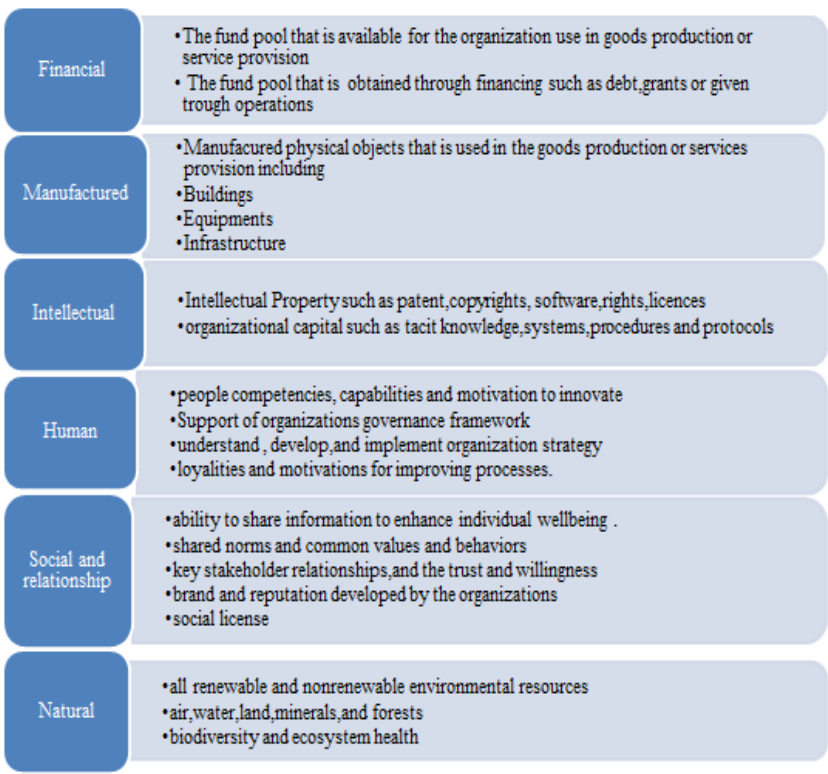

Fig.2. Description of the IIRC capitals(Source: Author, based on the IIRF)

All stakeholders are assisted by the integrated report in order to be able to create value over time. The core purpose of integrated report is to clarify how the business creates value to financial capital sources, staffs, clients, providers, business partners, local groups, representatives, managers and policy

The IR framework is determined by integrated thinking, which should guide to the creation of value through integrated decision-making and implementation.

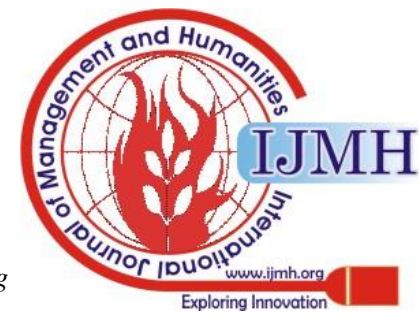


Integrated thinking stimulates organizations focusing on connectivity and interdependencies between different factors that have a significant impact on their capability to create value (Busco et al., 2013). Integrated reporting should therefore increase connectivity. The external report should be based on internal management information which should be reliable, independently verifiable.

The accountant can be called a value creator, value enabler, value maintainer and value reporter. Moreover, accountant could be a communicator, manager and business leader. In addition, integrated reports should also be flexible and developable (Owen, 2013).

Figure 3 shows the steps to go from integrated thinking to integrated reporting.

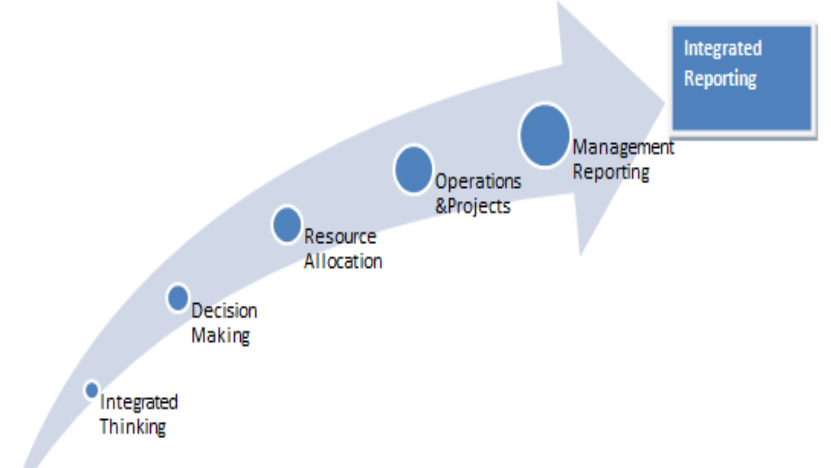

Fig.3.Path to reach integrated reporting

(Source: Author, based on the IIRF)

A quantitative and qualitative information combination should report an organization's capability to create value. An integrated report makes the connectivity of information explicit in order to communicate the creation of value over time (IIRC, 2013). The materiality concept should be considered when composing the integrated report.

It can be concluded that the integrated report includes activities, relationships and interactions with material impact on an organization's capability to create value (IIRC, 2013).

Finally, the utmost vital characteristics of integrated reporting are:

The creation of value of various principals over time, taking into consideration the short and long-term values and integrated, and

- A modification in decision-making processes, communication processes, substantive processes and risk identification should be affected by the first preparation of integrated report (Adams, 2015).

Other advantages identified in the preceding studies are:

- Greater accuracy in the non-financial information provided;

- Greater confidence levels for basic users; superior recognition of opportunities

- Higher engagement to investors and other collaborator Improved public appearance (Frias-Aceituno et al., 2014).

Against the recommended advantages of integrated reporting, not everyone strengthens the adoption of an integrated report. Following the launch of the IIRC's integrated reporting framework in 2013, many authors criticize this version of the framework. They argue that accounting is a social structure that can be used as a political instrument (Rodrigue, 2015). His study spotlight on the link between accountability, human rights and public disclosure policy aspects.

There will be having some challenges in adopting especially in producing a perfect integrated report. The companies may face difficulties especially fulfilling the criteria required by the integrated reporting. The researcher believes that the Malaysian companies have the basics of reporting covered in the businesses but they still have a long way to go to truly embrace (The Accountants Today Editorial Team, 2014). Although the companies in Malaysia have include Corporate Social Responsibility (CSR), sustainability and risk reports for the investors. However, they are not coherent in the sense that there is no linkage between all the information. In order to link the information and create value over the time, the companies need to face challenges in adopting this reporting .In order to provide a forward-looking statements in their annual reports, the organizations will be facing challenges, for example, time consuming in implementing internally and getting alignment across stakeholders groups. They have to think of some considerations in adopting at the starting stage and implementing it in the long run. These considerations will be the challenges to the organizations.

According to Flower (2015) the IIRC has failed. This judgement is based on a comparison of the IIRC's current proposals with its objectives. In four important areas the current proposals represent a repudiation of its original objectives:

a. The single report: The Integrated Report is not to become the firm's primary report; it is an extra report alongside conventional financial statements and sustainability reports, hence adding to the 'reporting landscape of confusion, clutter and fragmentation' which the IIRC so vividly criticized in its 2011 Discussion Paper. See Section 4.1 above.

b. Sustainability: The Integrated Report is not to cover sustainability -

c. Stakeholders: The Integrated Report is not to cover in a comprehensive fashion the impact of the firm's activities on stakeholders - see Section 5.2 above.

d. Lack of impact: The IIRC places very few specific obligations on the preparer of an Integrated Report. It seems highly likely that the IIRC's proposals will have very little impact on the financial reporting of companies which will not change significantly.

One of Flower's (2015, p. 1) major criticisms of and the IIRC is that, despite its founding principle to promote sustainability in accounting, the release of the Framework in 2013 abandoned sustainability accounting, and this has subsequently become another barrier to implementation. Flower's view was initially outlined by Milne and Gray (2013, p. 20) who argued "the IIRC's discussion paper, Towards Integrated Reporting is a masterpiece of obfuscation and avoidance of any recognition of the prior 40 years of research and experimentation" and "despite its claims for sustainable development and sustainability, it is exclusively investor focused and it has virtually nothing - and certainly nothing substantive - to say about either accountability or sustainability"
Blue Eyes Intelligence Engineering

\& Sciences Publication

(C) Copyright: All rights reserved.

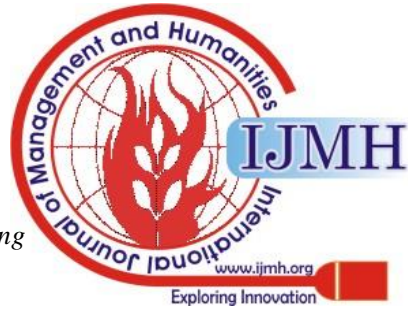


According to Adams (2015), the integrated reporting purpose is not to address sustainability, but to shift the target of reporting to long - term comprehensive thinking about strategy, methods of value creation and the business model.

The adoption of integrated reporting in lebanon was not studied before, this study aims to fill this gap. Therefore, in light of this, the research questions are the following:

RQ1: What are the factors affecting the adoption of Integrated Reporting?

RQ2: Does the expected challenges affects the adoption of Integrated Reporting?

\section{METHODOLOGY}

This study investigates the variable affecting the adoption of integrated reporting in Lebanon. Many researches were made worldwide about the adoption of integrated reporting however it is the first time covering the Lebanese sector.

In order to reach the objectives of our study, quantitative and qualitative methods will be conducted in order gather data that supports the main research goals. First, the universal separation between qualitative and quantitative research is that qualitative research objective is to create a new theory, while quantitative research attempts to examine hypotheses and offered theories (Bryman \& Bell 2003, p. 27).

The quantitative method will be achieved through using questionnaires that will be distributed to accountants managers , institutional employees and auditors from different business fields in the Lebanese sector including banks, audit companies . By definition, data collection is the process in which primary data are collected from samples through surveys, questionnaires and interviews to answer the research question or problem in order to produce original research results (Bryman \& Bell, 2015). Questionnaires have been the easiest and fastest method of data collection.

The questionnaires were distributed using Google form to local and international companies in Lebanon , this was made to ensure that the respondents remain anonymous and feel free to fill the questionnaire freely without any pressure from subordinates. One hundred twenty questionnaires were distributed however twenty two were excluded because they are either partially filled or kept blank. The questionnaire involves 22 questions that discuss the information about the adoption of integrated reporting the questionaire is divided into three sections starting with qualifying information to know the awarness of the respondant to inegrated reporting and if he is occupying a position in the accounting department inorder to check if they are elegible for answering the questionnaire and then questions covered to know their view on integrated reporting . Likert scale of 1 to 5 ( " 1 " strongly agree, "2" agree, " 3 " normal, "4" disagree, "5" disagree)was adopted in the questionnaire to test the agreement or disagreement of the participant with the expected challenges facing in the application of integrated reporting mentioned in literature, and to give their opinion based on real scenarios encountered from their experience. The data were analyzed using SPSS software where the mean and standard deviation were generated and interpreted to investigate the respondents understanding of the factors affecting the adoption of integrated reporting .The research practice is founded on exploring the literature review subjects written about the adoption of integrated reporting and the importanceof this adoption .

Also a descriptive analysis is applied in this study. Descriptive statistics are used in a controllable form to display quantitative descriptions. This method helps us to reasonably simplify large amounts of data. It reduces many data to a simpler summary. Regression analysis was conducted to verify the relation between the dependent variable (Adoption of integrated reporting) and the independent variables (Education, and Occupying a position in the accounting department). In order to be able to apply multiple regression, multicollinearity must be checked to exclude the correlated values with the lower level of significance. Multiple regression between the dependent variable (Adoption of integrated reporting) and the independent variables (Education and Occupying a position in the accounting department) proved that there is a significant impact of the independent variable on the adoption of integrated reporting.

The Cronbach's value for each of the expected challenges in the application of integrated reporting involved in the study is found to be reliable since each value is above 0.7 as shown in

Table- I: which is acceptable as reported in (Hair et al., 2013).

\begin{tabular}{|c|c|}
\hline $\begin{array}{c}\text { Expected challenges in the application of } \\
\text { integrated reporting }\end{array}$ & Cronbach's Alpha \\
\hline $\begin{array}{c}\text { The cost of implementation of integrated } \\
\text { reporting relative to the benefits. }\end{array}$ & 0.724 \\
\hline $\begin{array}{c}\text { Time needed to replace the currently } \\
\text { applicable reports. }\end{array}$ & 0.726 \\
\hline $\begin{array}{c}\text { Subjectivity of information included in the } \\
\text { report. }\end{array}$ & 0.827 \\
\hline Reliability of information reported. & 0.717 \\
\hline Expertise and skill needed. & 0.826 \\
\hline
\end{tabular}

\section{RESULTS AND DISCUSSION}

We collected the questionnaires and analysed the results according to responses. We will present a descriptive analysis of the results and the regression analysis results. Gender. Figure 4 depicts the respondents' demographic according to the gender. Of the $n=98$ participants, $64 \%$ were female $(n=63)$ and $35 \%$ were male $(n=35)$. Female respondents were more outgoing and willing to participate in the area the research was conducted. This research result on gender can be related to Thompson and Conradie (2011:45), who mention that women's willingness to participate in community duties is motivated by their instinct as women to protect and secure an acceptable socio-economic level for the wellbeing of their families. 


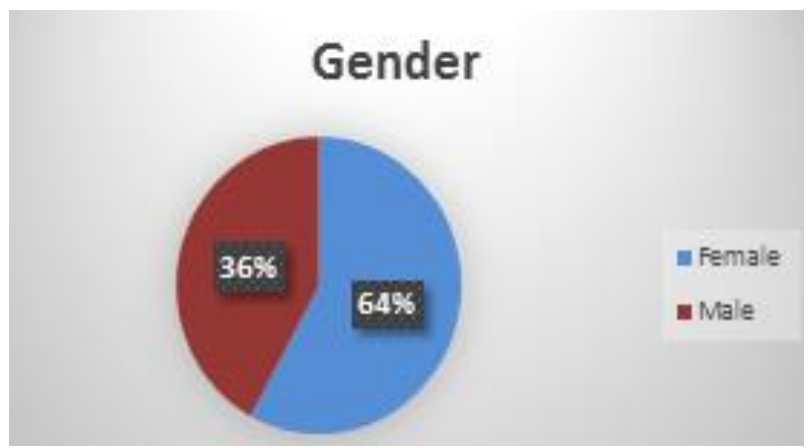

Fig.4. Gender (Source: Author's projection)

Participants' age. The questionnaire had a category of age designed to describe a respondent's age. Respondents were asked to choose their respective categories of age. Figure 5 captures how the age was considered and what the responses were in each of the categories. This figure shows that the majority of respondents, $n=49(50 \%)$, were aged between 20-30 years. The second-highest category with the frequency of $n=42(42.9 \%)$ were respondents categorized between $30-40$ years old. With a frequency of $n=7,7 \%$ were over 40 years old. From the research result, the majority of respondents were young.

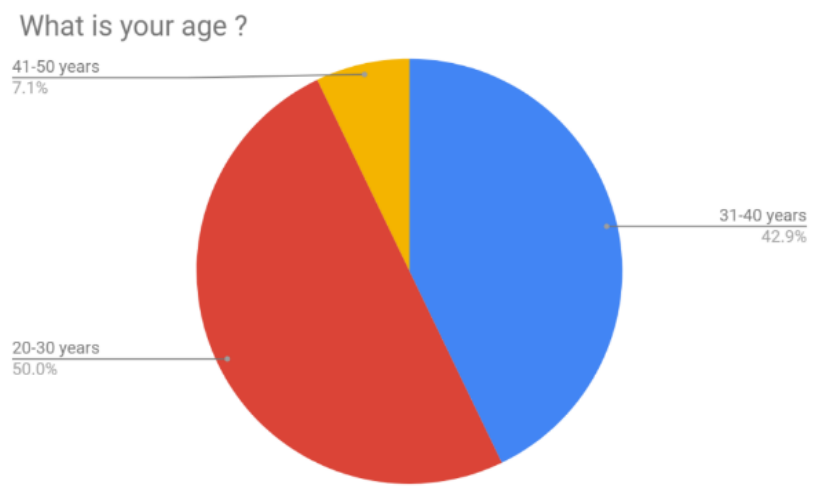

Fig.5. Participants' age (Source: Author's projection) Position occupied. The questionnaire had a question to identify the position occupied for the participant. Respondents were asked to answer if they are occupying a position in the accounting department. Figure 6 shows that the majority of respondents, $n=63(64.3 \%)$, are occupying position in the accounting department and only $n=35$ (35.7\%) are not occupying a position in the accounting department. From the research result, the majority of respondents are occupying position so this will make our research more valid.

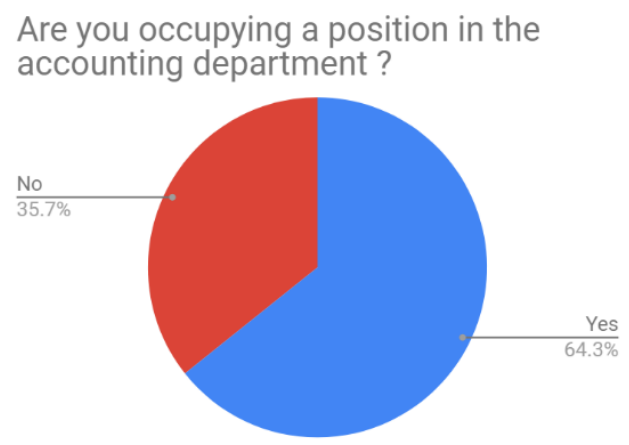

Fig.6. Position occupied (Source: Author's projection)

Integrated reporting awareness. The most common result concerning whether the employees are aware of integrated reporting of the area the research where conducted were
"Yes" with an $n=77$ representing (78.6\%), answers that they are aware of integrated reporting. The remaining $n=21$ representing $(21.4 \%)$ results were "no", they answered that they are not aware of integrated reporting. This means that the majority of the employees in the accounting department are aware of integrated reporting. Figure 7 represents the employee's awareness of integrated reporting

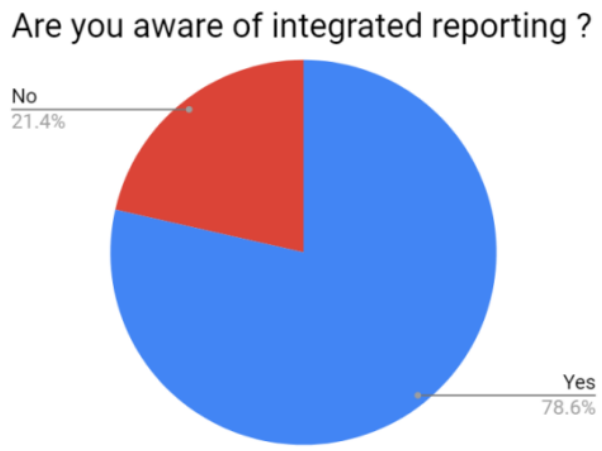

Fig.7.Employee's awareness of integrated reporting (Source: Author's projection)

Collecting financial data and preparing financial reports. The question was asked to identify the responsibility of the respondent in the accounting field. The result shows an important factor in the answers of the respondents where $\mathrm{n}=77(78.6 \%)$ are responsible for collecting data and preparing financial reports and only $n=21$ (21.4\%) answered No. The result also shows that the majority of the respondents are responsible for data collection and reporting.

\section{Are you responsible for collecting financial data and preparing financial reports?}

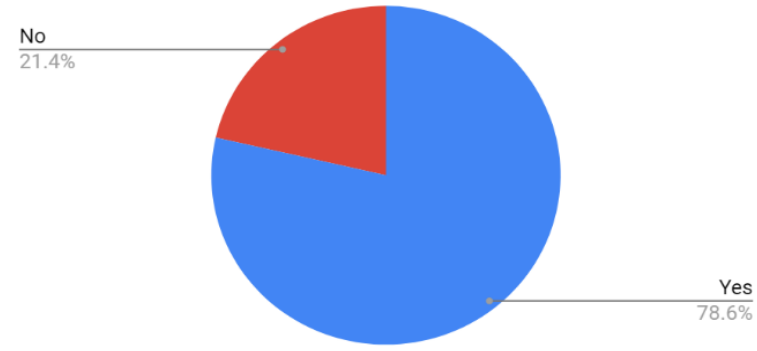

\section{Fig.8. Respondent's responsibilities (Source: Author's} projection)

Reasons for adopting integrated reporting. The question was asked to identify the reason for adopting integrated reporting. The question was to tick the reasons for adopting integrated reporting, the choices were the following, pressure from regulators, desire to implement integrated thinking within your organization, direction from management, pressure from investors and market needs. The result shows the major reasons as shown in Figure 8 is desire to implement integrated thinking within your organization where $n=35$ respondents choose it where seven of respondents they answered desire to implement integrated thinking within your organization and market needs and $n=7$ answered desire to implement integrated thinking within your organization and direction from management and $n=7$ they answered desire to implement integrated thinking within your organization and pressure from investors.

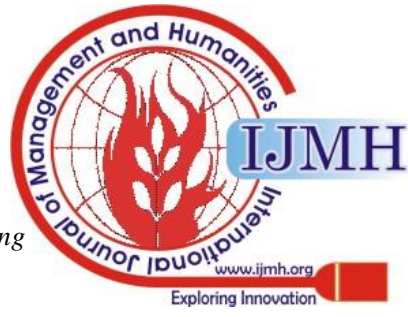


The results show also that the majority of the respondent answered they are willing to implement integrated thinking within your organization.

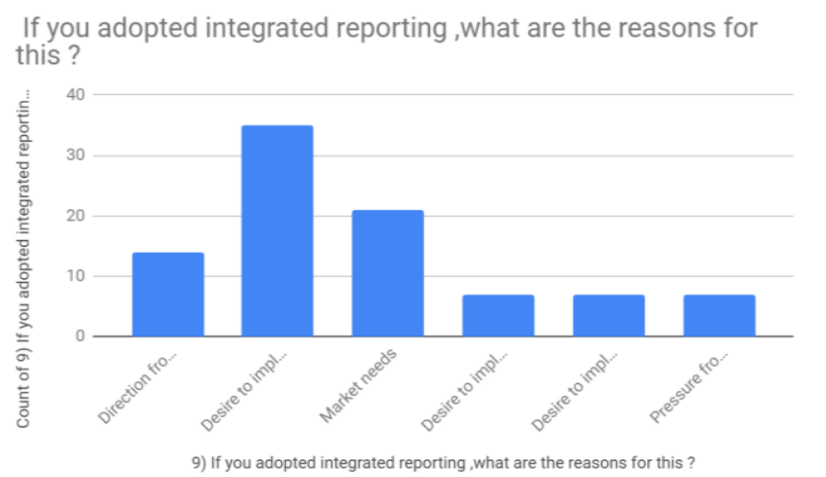

Fig.9.Respondent's reasons for adopting integrated reporting

(Source: Author's projection)

Integrated reporting ways of improvement. The question was asked to identify what will improve the adoption of integrated reporting. The question was to choose between higher awareness of integrated reporting and its goals, stronger endorsement from leading company, guidance to help preparers, evidence of benefits and training and guidance from established and approved providers. The major reason as shown in Figure 10 is higher awareness of integrated reporting and its goals.

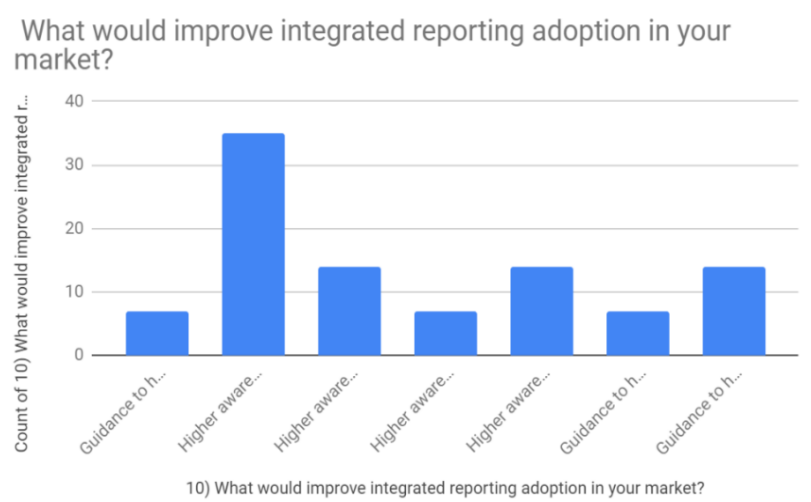

Fig.10.Improvement for adopting integrated reporting (Source: Author's projection)

Integrated reporting adoption. The question was asked to identify if the adoption of integrated reporting will give leading practice ability in the market. As shown in the figure 10 where $n=84(85.7 \%)$ of the respondents answered "Yes" and only $n=14(14.3 \%)$ answered "No".

Does the adoption of integrated reporting give your company a leading practice ability in the market?

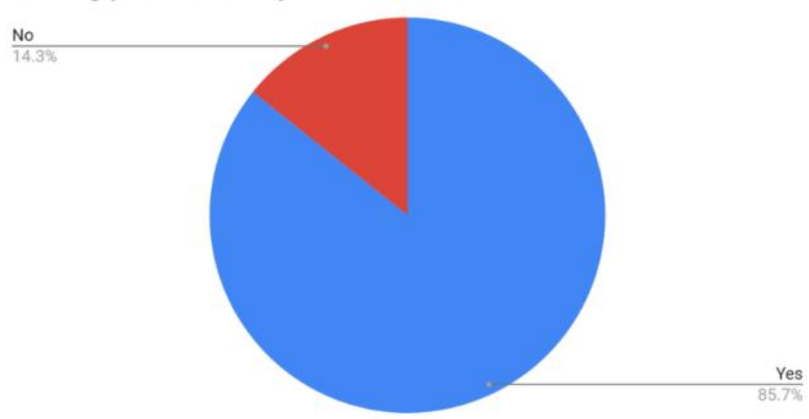

Fig.11.Integrated reporting adoption (Source: Author's projection)
Current corporate reporting satisfaction. The question was asked to identify the level of satisfaction with the current corporate reporting. The results show that only $n=37$ (37.8\%) are satisfied with their corporate reporting where the majority of the respondents are not satisfied representing 53.1\% so there is a need to adopt integrated reporting in the market.

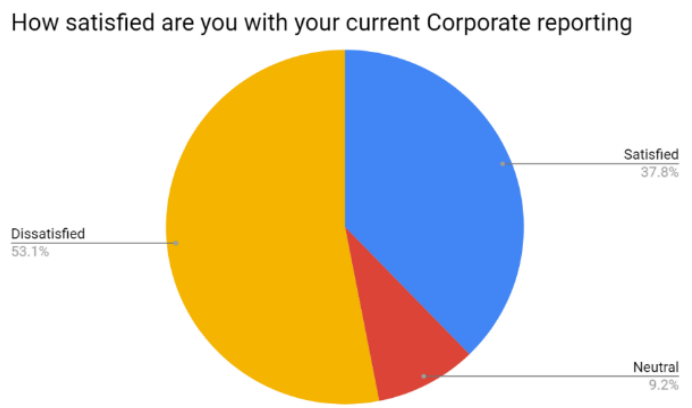

Fig.12.Current corporate reporting satisfaction (Source: Author's projection)

Statistical relationship

We applied regression analysis in order to find answers to the the first and second research question (Methodology section). Inorder to answer the first research question,regression analysis was conducted to verify the relation between the dependent variable (Adoption of integrated reporting) and the independent variables (Education, and Occupying a position in the accounting department).

Table- II: Regression analysis

Dependent Variable: ADOIR

Method: Least Squares

Date: 05/05/19 Time: 14:02

Sample: 198

Included observations: 98

\begin{tabular}{llll}
\hline & \multicolumn{3}{c}{ Std. } \\
Variable & Coefficient Error & t-Statistic Prob. \\
\hline EDU & 0.411093 & 0.0525817 .8183120 .0000
\end{tabular}

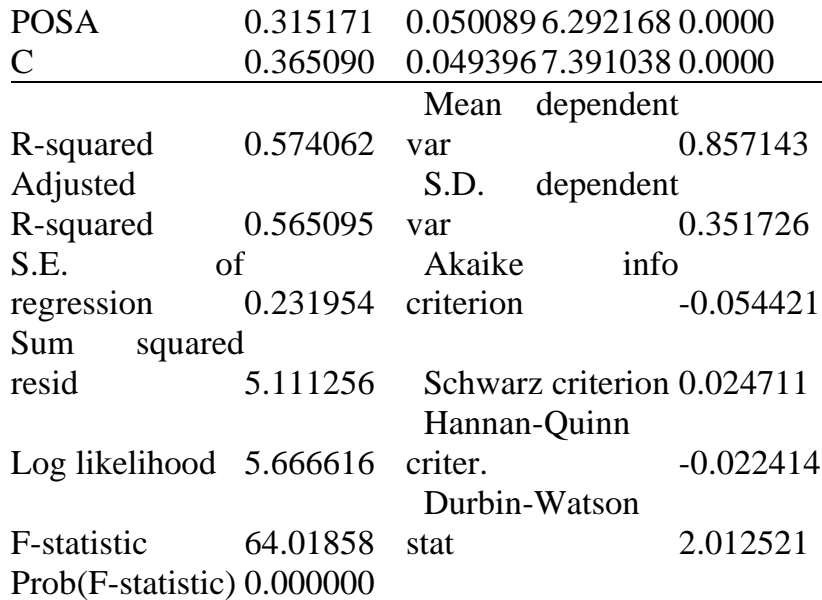

ADOIR is referred to the adoption of integrated reporting ( $1=$ Yes, $0=$ No).

POSA is referred to Occupying a position in the accounting department ( $1=$ Yes, $0=$ No).

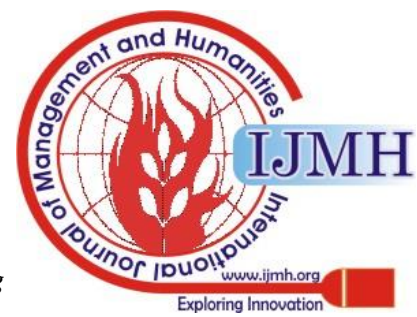

(C) Copyright: All rights reserved. 
EDU: is referred to Education (Bachelor =0, Masters =1).

(Source: Compiled by the author)

The below equation was shown in table 1:

ADOIR=0.411 EDU + 0.315 POSA +0.365

$\mathrm{R}$-squared is a goodness-of-fit measure for linear regression models. It indicates the percentage of the variance in the dependent variable that the independent variables explain collectively. R-squared measures the strength of the relationship between the model and the dependent variable on a convenient $0-100 \%$ scale. The R-squared is equal to 57 percent of the variation in $\mathrm{y}$ is explained by the variation in predictors EDU \& POSA. R-squared of $57 \%$ reveals that $57 \%$ of the data fit the regression model. So the adoption of integrated reporting in Lebanon is affected by the educational background of the employees and the if they are occupying positions in the accounting department.

We then applied regression analysis in order to study the impact of the expected challenges on the application of integrated reporting(Second research question ). Whenever regression analysis is considered, there are prerequisite tests to be taken into consideration before running the regression. First, data must be tested if it is normally distributed or not. Second, multicollinearity is a must to investigate if the independent variables are dependent on each other.

Table2 shows the skewness - kurtosis results. Hair (et al., 2013) indicates that the range between -2.58 and +2.58 with significance level less than 0.01 is a sign of normal distribution. Since all the skewness values fall within the range. Hence, we can conclude that we have a normal distribution.

Table- III: Skewness - Kurtosis test

\begin{tabular}{|c|c|c|}
\hline $\begin{array}{c}\text { Expected challenges in the application of } \\
\text { integrated reporting }\end{array}$ & Skewness & Kurtosis \\
\hline $\begin{array}{c}\text { The cost of implementation of integrated } \\
\text { reporting relative to the benefits. }\end{array}$ & -.419 & -1.889 \\
\hline $\begin{array}{c}\text { Time needed to replace the currently applicable } \\
\text { reports. }\end{array}$ & -.409 & -1.129 \\
\hline $\begin{array}{c}\text { Subjectivity of information included in the } \\
\text { report. }\end{array}$ & -.625 & -.774 \\
\hline Reliability of information reported. & -.237 & -.607 \\
\hline Expertise and skill needed. & -.731 & .456 \\
\hline
\end{tabular}

Table 3 shows the collinearity results where the tolerance of all variables are above 0.2 and all VIF values are less than 10 . The variance inflation rate and tolerance are used in order to test the degree or dependency or noninterference of the independent variables with each other. Tolerance value above 0.2 is an indicator that independent variables are not correlated with each other and VIF value less than 10 gives the same interpretation (Hair et al, 2013). The results of the above table reveals the independence of the variables under study.

The statistical results confirms the independence of variables. Consequently, we can apply regression analysis to support the third research question.

H0: There is no significance influence of cost, time needed to replace the current report , Subjectivity of information included in the report, Reliability of information reported, Expertise and skill needed.on the success adoption of integrated reporting.
Table- IV: Collinearity Results

\begin{tabular}{|c|c|c|}
\hline \multirow{2}{*}{ Model } & \multicolumn{2}{|c|}{ Collinearity Statistics } \\
\cline { 2 - 3 } & Tolerance & VIF \\
\hline $\begin{array}{c}\text { The cost of implementation of } \\
\text { integrated reporting relative to } \\
\text { the benefits. }\end{array}$ & .666 & 1.501 \\
\hline $\begin{array}{c}\text { Time needed to replace the } \\
\text { currently applicable reports. }\end{array}$ & .547 & 1.830 \\
\hline $\begin{array}{c}\text { Subjectivity of information } \\
\text { included in the report. }\end{array}$ & .634 & 1.576 \\
\hline $\begin{array}{c}\text { Reliability of information } \\
\text { reported. }\end{array}$ & .467 & 2.140 \\
\hline Expertise and skill needed. & .404 & 2.473 \\
\hline
\end{tabular}

Table- V: Regression Summary Results

\begin{tabular}{|c|c|c|c|c|c|c|}
\hline Model & $\mathrm{R}$ & $\begin{array}{c}\mathrm{R} \\
\text { Square }\end{array}$ & $\begin{array}{c}\text { Adjusted } \\
\mathrm{R} \text { Square }\end{array}$ & $\begin{array}{c}\text { Std. } \\
\text { Error of } \\
\text { the } \\
\text { Estimate }\end{array}$ & F value & $\begin{array}{c}\text { Sig. F } \\
\text { Change }\end{array}$ \\
\hline 1 & .818 & .665 & .638 & 4.855 & 26.649 & .000 \\
\hline
\end{tabular}

Tables 5 illustrate that the statistical value $F$ is 26.649 with a level of significance lower than 0.05 which highlights that there is a significant statistical impact of cost of implemtation,time needed to replace current reporting,subjectivity of information included in the report, reliability of information and expertise and skills needed on the adoption of integrated reporting . Thus, rejecting the null hypothesis and accepting the alternative hypothesis.

\section{CONCLUSION}

An integrated report tries to tell a story about the journey of an organization to reach its vision, reporting on its historical and intended performance. Most importantly an organization should demonstrate that its focused tactics and strategies underlie its values and are enacted towards reaching the vision during the reporting period.

Integrated reporting should make accountability and performance in an organization transparent, but depends on the ethical qualities (such as honesty, fairness) embedded in the organization's values being upheld.

The main purpose of this paper was to find out why companies are slow at adopting IR and what needs to be done to ensure the adoption of integrated reporting and to analyse the process of adopting integrated reporting and the benefits deriving from the implementation of this practice .

From the practical perspective, implementing IR could be complex, but what it can do for business entities is notable.

Results suggest that firms are slow to adopt IR because of the scarce and minimal resources, culture and leadership, stakeholders demand, the regulatory requirement, the effect of globalization and the mind-set, lack of awareness about IR and the nature of business and size.

The results show, first of all, that the process of implementing integrated reporting is the result of a clear desire of top management. This demonstrates the importance of corporate culture in the process of adopting integrated reporting (Vitolla et al., 2016).

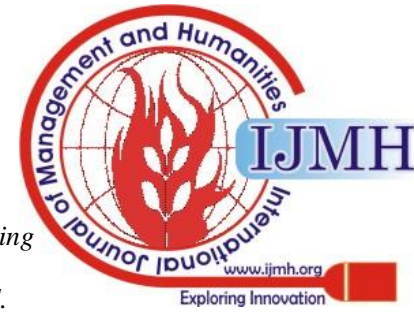


Therefore, the pressures of external stakeholders are not enough, but it is necessary that the change starts from within the company through a corporate culture devoted to sustainability and transparency.

Secondly, the results show that the adoption of integrated reporting has had positive impact on the company. In fact, favourable reactions were recorded by analysts who recognized a higher quality of external reporting combined with a greater readability of documents. The stakeholder engagement activity also benefited from the adoption of integrated reporting.

Henceforth, this paper would like to recommend every business entity to adopt IR as their business reporting tool by each business entity in Lebanon. It is evident after the discussion that integrated reporting is the most operative method to communicate with stakeholders, demonstrating a company's whole image of upcoming aims and links between financial enactment and reporting on firm community and environmental accountabilities. IR also helps with its integrated thinking and decision-making process to improve the business model and strategy.

The results obtained confirm what has been said in the literature regarding the positive effects of integrated reporting. The most surprising aspect is that related to the strong positive impacts within the company, since generally reporting is considered an instrument that is mainly addressed to external stakeholders. This work contributes to the literature on the topic by providing empirical evidence on the positive effects of integrated reporting and shedding light on the way in which the implementation process of this practice is launched.

There are still a challenge for the companies to adopt integrated reporting. Cost is the most consideration for the organization and also the availability, the readness of information as well as the ability of report preparers will affect the decision of management in considering to adopt and implement the integrated reporting in their organizations.

\section{REFERENCES}

1. Adams, C. (2013), Understanding Integrated Reporting: The Concise Guide to Integrated Thinking and the Future of Corporate Reporting. London: DoShorts.

2. Adams, C. A. (2015), "The International Integrated Reporting Council: A call to action", Critical Perspectives on Accounting, Vol. 27 No. 1, pp. 23-28.

3. Bryman, A., \& Bell, E. (2003). "Breaking down the quantitative/qualitative divide". Business Research Methods, pp. 465-478.

4. Busco, C., Frigo, M.L., Quattrone, P., \& Riccaboni, A. (2014), "Leading Practices in Integrated Reporting”. Strategic Finance, September, pp. 23-32.

5. Eccles, R. \& Krzus, M. (2010), One Report: Integrated Report for a Sustainable Strategy. New York: Wiley.

6. Flower, J. (2015), “The International Integrated Reporting Council: a story of failure", Critical Perspectives on Accounting, Vol. 27, pp. 1-17.

7. Frias-Aceituno, J.V., Rodríguez-Ariza, L., \& Garcia-Sánchez, I.M. (2014), "Explanatory factors of integrated sustainability and financial reporting". Business Strategy and the Environment, 23, 56-72.

8. Hair, J.F., Ringle, C.M. and Sarstedt, M., 2013. Partial least squares structural equation modeling: Rigorous applications, better results and higher acceptance. Long range planning, 46(1-2), pp.1-12.

9. IIRC. (2011), Towards Integrated Reporting: Communicating Value in the 21st Century. International Integrated Reporting Council, Discussion Paper, London.

10. International Integrated Reporting Council, (IIRC). (2013), The International Integrated Reporting Framework. London: International Integrated Reporting Committee, IIRC.

11. Milne, M.J. and Gray, R., 2013. W (h) ither ecology? The triple bottom line, the global reporting initiative, and corporate sustainability reporting. Journal of business ethics, 118(1), pp.13-29.
12. Owen, R. (2013). State, power and politics in the making of the modern Middle East. Routledge.

13. Rodrigue, M. (2015). "The International Integrated Reporting Council: A Story of Failure; 'But Does Sustainability Need Capitalism" or "An 'Integrated Report' A Commentary on The International Integrated Reporting Council: A Story of Failure" by Flower, J.; The International Integrated Reporting Council: A Call to Action. Social and Environmental Accountability Journal, 35(2), pp. 128-129.

14. Thompson, L. \& Conradie, I. (2011). From poverty to power? Women's participation in intermediary organisations in site $C$, Khayelitsha. Africanus, 41(1), pp. 43-56.

15. Vitolla, F., Rubino, M. and Garzoni, A., 2016. Integrated corporate social responsibility: Driving factors and means of integration-a multiple case study analysis. Journal of Management Development, 35(10), pp.1323-1343.

\section{AUTHORS PROFILE}

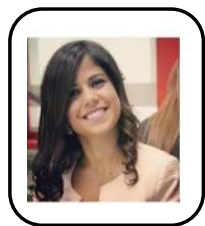

Malak Bou Diab , a Phd student at Bucharest University of Economic Studies, Romania .An Accounting Instructor, Advisor and Coordinator at Lebanese International University .She received her Bachelor Degree and her Master of Business Administration in Accounting Information System degree from the Lebanese International University.

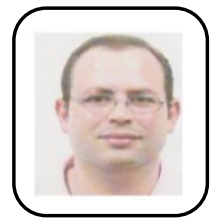

Wissam El Hajj, $\mathrm{He}$ is a lecturer at Lebanese International University. He received his undergratuate degree in Business Administration at American University of Beirut. After earning experience of three years in insurance accounting, he entered the MBA program at the Lebanese International University. He is economic studies. completing his phd at the bucharest university of

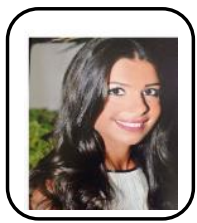

Vera Bou Diab, a personal banker at Bybkos Bank for 6 years. she received her Bachelor Degree and her Master of Business Administration in finance degree from the Lebanese International University. 